\title{
In defence of situational ethics, the NHS and the permissive society
}

\author{
Sir Douglas Black Emeritus Professor of Medicine, Manchester University
}

\section{Author's abstract}

Dr Adrian Rogers delivers a three-pronged assault on the concepts of 'situational ethics'; the eleemosynary* principles underlying the National Health Service, and the permissiveness of modern society. I hold strong, and largely opposite, views on each of these matters, which are outlined in this paper.

\section{Situational ethics}

I have both admiration and sympathy for those who are required, or who volunteer, to formulate codes of ethics. But such codes only acquire real meaning when they are translated into conduct in concrete situations; or, as St James put it 'Faith without works is dead'. In a part of the world during the 'ages of faith', there was a religious consensus, perhaps more apparent than real, on which a theogenic code of ethics could plainly be based; this situation, rightly or wrongly, no longer obtains, and it seems to me to be simple arrogance on the part of doctors to set their own code of ethics absolutely above the wishes and interests of their patients, who come in their infinite variety. Of course, I believe that at the end of the road there are things which no doctor should do ; but the situation in which such matters arise cannot be neglected. So on balance, I place more emphasis on relationships and on situations, and comparatively less on codes, which if they are to be sensible, can only define a minimum standard, whereas we should try to do better.

\section{The National Health Service}

I accept that people have the right to spend money in the pursuit of health, even though the success of doing so is not guaranteed; and I have many friends who practise medicine to the highest standards, in spite of being to some extent paid privately for doing so. But I have never accepted the argument advanced by $\mathrm{Dr}$ Rogers that the relationship between a patient and his or her doctor is in general enhanced by the passage of a fee between them. I know that some patients believe this also, on the same principle that raising the price of luxury goods can sometimes enhance sales. But to the generality of people (and I speak not only for the Scots) a fee may be at best a deterrent, and at worst something which they simply cannot afford - are they then to be neglected? Also, I find some of Dr Rogers's examples unconvincing. If it is difficult, as he says, and as I would deny, to persuade family doctors to do homevisits without a fee, how would he explain the situation in the USA, where the charismatic effect of a fee is scarcely reflected in a plethora of domiciliary visits.

\section{The permissive society}

I have the weakness of sympathising with some aspects of the contentions of those with whom in general I disagree; and on this third matter a scintilla of sympathy with Dr Rogers appears, no doubt because of my Puritan upbringing. I have little sympathy with those who glorify aberrant behaviour of all kinds, and less still when it constitutes a threat to others, going beyond a private indulgence. But I also suspect that the two veneers, respectively of hypocrisy and of shamelessness, may conceal realities of behaviour which are not too dissimilar. And in any case, the tone to be set in this matter is surely a decision for society as a whole, and not just for doctors as such, though of course as citizens we are entitled to a view. When it comes to practice, I think our duty to our patients consists in acquainting them with specific health hazards inherent in their way of life, not with setting ourselves up as censores morum. I accept that this advocacy of a certain seemly reticence may arise from chicken-heartedness - but at least I can be bold in declaring it.

^Charitable - Ed.

\section{Key words}

Medical ethics; situational ethics; National Health Service; the permissive society. 